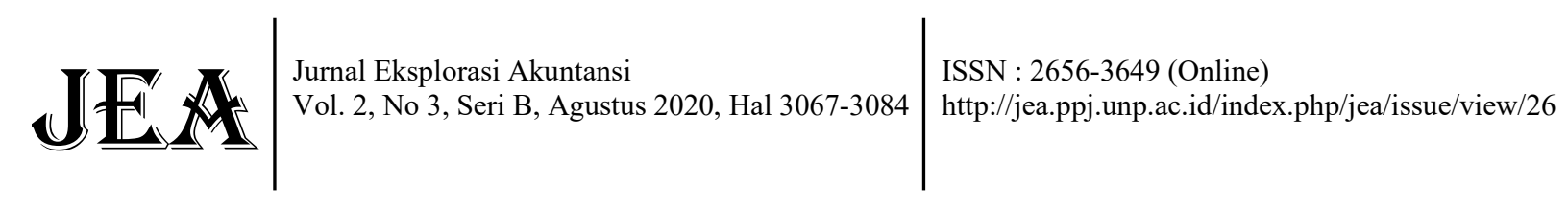

\title{
PENGARUH RESPON ORGANISASI DAN POWER DISTANCE TERHADAP NIAT MELAKUKAN WHISTLEBLOWING
}

\author{
Aning Santi Lestari ${ }^{1}$, Sany Dwita ${ }^{2}$ \\ ${ }^{1}$ Alumni Jurusan Akuntansi Fakultas Ekonomi Universitas Negeri Padang \\ ${ }^{2}$ Jurusan Akuntansi Fakultas Ekonomi Universitas Negeri Padang \\ *Korespodensi: aningsantilestari@gmail.com
}

\begin{abstract}
This study investigates a number of factors influencing employees to report unethical behavior in their organizations. This study aims to empirically examine the effect of organizational response on whistleblowing intentions, the effect of power distance on whistleblowing intentions. This research uses quasi-experimental design. The difference between this research and previous research is in the research data sources. This study collected data with a survey questionnaire given to 64 accounting students from a university in Padang, the capital of West Sumatra. Data were analyzed using ANOVA. The results of this study indicate that strong organizational responses do not have a negative impact on whistleblowing intentions. We also find that low power distances have a positive impact on whistleblowing intentions. The results of this study indicate that power distance affects the intention of revealing facts. These results contribute to the existing literature on accounting ethics, as well as inform public accounting governance policies
\end{abstract}

Keywords: Whistleblowing; Organizational Response; Power Distance

How to cite (APA $6^{\text {th }}$ style):

Lestari, A. S. \& Dwita, S (2020). Pengaruh Respon Organisasi dan Power Distance terhadap Niat Melakukan Whistleblowing. Jurnal Eksplorasi Akuntansi, 2(3), Seri B, 3067-3084.

\section{PENDAHULUAN}

Whistleblowing telah menarik perhatian dunia untuk saat ini dan bukanlah fenomena baru namun sudah lama terjadi diberbagai negara (Nurhidayat, 2017). Whistleblowing merupakan kegiatan pengungkapan informasi oleh seseorang dalam organisasi kepada pihak-pihak tertentu akibat adanya pelanggaran atau kejahatan (Miceli et al., 2008). Seseorang yang melakukan whistleblowing disebut dengan whistleblower.

Kasus-kasus mengenai whistleblowing telah banyak terjadi di Indonesia yang membuat masyarakat tercengang (Yaya, 2017). Salah satu kasus whistleblowing dilakukan oleh Ferry Pasaribu, mantan General Manager Divisi Sistem Manajemen dan Informasi Teknologi PT Sarinah (Persero) yang sudah tiga kali membuat laporan dugaan korupsi. Pelaporan yang dibuat 
Ferry merupakan salah satu bentuk kecintaan terhadap Sarinah tempat ia telah bekerja selama 23 tahun, serta bentuk tanggungjawabnya sebagai ketua IKS. Akan tetapi, laporan tersebut bocor ke Direksi Sarinah yang mengakibatkan Ferry dipecat dengan alasan membocorkan rahasia perusahaan (CNN, 2015).

Selain kasus di PT Sarinah, kasus whistleblowing lainnya yang terjadi di Indonesia adalah; Kasus Yohanes Waworuntu mantan Direktur Utama PT. Sarana Rekatama Dinamika (SRD) yang mengungkapkan skandal pengadaan Sistem Administrasi Badan Hukum (Sisminbakum) Kementerian Hukum dan Hak Asasi Manusia sehingga mengakibatkan Yohanes Waworuntu dipecat dan di penjara selama 3 tahun karena diduga terkait dalam kasus Sisminbakum. Kasus Agus Tjondro, yang mengukap kasus suap kepada sejumlah anggota DPR dalam pemilihan Deputi Senior Gubernur BI, Murdiyanto. Agus Tjondro mengaku telah menerima cek pelawat (traveller cheque), pengakuan tersebut menjadikan status Agus Tjondro sebagai saksi pelapor atau whistleblower dan juga berstatus sebagai tersangka. Kasus-kasus tersebut menunjukkan bahwa whistleblower rentan atas pembalasan dan minim perlindungan serta memperlihatkan kepada publik bahwa menjadi whistleblower dapat merugikan diri sendiri.

Pembuat kebijakan di Indonesia telah menciptakan peraturan-peraturan yang mendorong untuk melakukan tindakan whistleblowing serta memberikan perlindungan kepada whistleblower. Kebijakan whistleblowing di Indonesia telah ada melalui penguatan dan dorongan yang diberikan melalui tata cara pelaporan yang rahasia dan terenkripsi (OJK, 2015; KBUMN, 2016). Kebijakan tersebut tidak membuat masyarakat Indonesia melakukan whistleblowing. Pada tahun 2004-2017, terdapat 100 ancaman atau serangan kepada whistleblower. Hal tersebut menunjukkan bahwa ancaman atau serangan terhadap whistleblower masih rentan, sehingga menurunkan niat seseorang untuk menjadi whistleblower karena sangat rawannya sanksi yang akan diterima terhadap tindakan pembalasan atau kejahatan. Status whistleblower bisa berubah menjadi tersangka atas tuduhan pencemaran nama baik. Selain itu tidak adanya respon dari laporan yang dibuat serta kedudukan pelanggar yang lebih tinggi dari whistleblower merupakan penyebab seseorang tidak melakukan tindakkan whistleblowing (Taylor dan Curtis, 2013).

Penelitian Miceli et al., (2008) menjelaskan bahwa respon dari laporan yang dibuat dapat memengaruhi whistleblower (pelapor) di berbagai titik dalam proses pengambilan keputusan mereka untuk melaporkan perilaku tidak etis, hasilnya menunjukkan bahwa karyawan tidak melaporkan kesalahan yang diamati karena tidak ada yang bisa atau tidak ada tindakan yang dilakukan untuk menghentikan pelaku. Taylor dan Curtis (2013) dalam penelitiannya menjelaskan bahwa adanya rasa hormat dan rasa takut terhadap pelaku pelanggaran karena memiliki kedudukuan yang lebih tinggi daripada dirinya (whistleblower) sehingga menjadi sungkan untuk melakukan whistleblowing.

Ahmad (2011) menyebutkan bahwa sebagian besar penelitian terdahulu menguji tentang whistleblowing berfokus pada empat faktor umum, yaitu faktor organisasi (Puni dan Anlensinya, 2017; Taylor dan Curtis, 2013; Wong-On-Wing dan Lui, 2013), faktor individu (Chiu, 2003; Erkmen dkk., 2014), faktor situasional (Keenan, 2000; Darjoko dan Nahartyo, 2017; Priyastiwi dan Halim, 2017) dan faktor demografis (Napitupulu dan Bernawati, 2016; Fajri dkk., 2017). Pemahaman tentang proses whistleblowing menjadi rumit karena kompleksitas variabel dan interaksi diantara variabel (Sims dan Keenan, 1998).

Selain empat faktor umum tersebut, keputusan untuk menjadi whistleblowing dipengaruhi oleh banyak faktor, salah satunya adalah faktor budaya (Finandari dan Wijayanto, 2016). 
Pengaruh budaya sangat alami dan otomatis sehingga pengaruhnya terhadap perilaku sering diterima begitu saja. Penelitian selanjutnya memerlukan identifkasi mengenai interaksi dari faktor-faktor tersebut seperti interaksi antara faktor organisasi dan faktor budaya (Taylor dan Curtis, 2013).

Penelitian terdahulu tentang respon organisasi terhadap whistleblowing yang dilakukan pihak internal, tidak menjelaskan secara langsung bahwa respon organisasi merupakan faktor yang menyebabkan seseorang berniat melakukan whistleblowing, penelitian tersebut diantaranya; Penelitian atas persepsi organisasi (Parmerlee et al., 1982), keadilan organisasi (Seifert dan Sweeney, 2010), keadilan organisasi, ketidaksetujuan organisasi, perbedaan pendapat organisasi (Taylor dan Curtis, 2012) keadilan organisasi, power distance, dan gender (Curtis et al., 2012), komitmen organisasi (Wijaya, 2016). Penelitian ini dilakukan untuk menguji secara khusus mengenai respon organisasi terhadap niat melakukan whistleblowing yang dilakukan oleh pihak internal organisasi, karena sebagian besar penelitian terdahulu menguji respon organisasi hanya secara umum.

Respon organisasi merupakan tindakan yang dilakukan organisasi ketika menerima laporan kesalahan (Taylor dan Curtis, 2013). Penelitian terdahulu yang dilakukan Taylor dan Curtis (2012) mendapatkan hasil bahwa respon yang cepat dan konsisten akan mendeteksi dan memperbaiki perilaku yang tidak etis sebelum menjadi kebiasaan. Sejalan dengan hasil penelitian Seifert dan Sweeney (2010) bahwa respon organisasi dapat mempengaruhi whislteblowing karena manajer yang mengambil tindakkan untuk mengidentifikasi perilaku tidak etis yang telah dilaporkan whistleblower menanganinya secara memadai dan membangun suasana organisasi yang positif akan mendorong whistleblower untuk melakukan whistleblowing sejak dini.

Setiap organisasi mempunyai budaya organisasi yang berbeda-beda dan telah mengakar pada dirinya. Budaya dapat mempengaruhi perilaku seseorang (Puni dan Anlensinya, 2017). Sejumlah penelitian lintas budaya dalam akuntansi mengacu pada dimensi nilai Hofstede. Berdasarkan demensi Hofstede (2011) indeks untuk mengukur enam dimensi budaya disetiap negara yaitu; power distance, individualism, masulinity, uncertainity avoidance, long term orientation, dan indualgence.

Sebagian besar penelitian tentang power distance digunakan untuk menjelaskan perbedaan perilaku antar budaya, kontras persepsi power distance dari peran yang sama di berbagai negara. Power distance didefinisikan sebagai sejauh mana anggota di suatu organisasi yang kurang kuat dalam suatu negara mengharapkan dan menerima bahwa kekuasaan di dalam organisasinya didistribusikan secara tidak merata (Hofstede, 2001). Menurut Santoso (2019) power distance adalah adanya jarak kekuasaan antara atasan dengan bawahan, power distance kerap kali lebih sering dirasakan oleh bawahan terhadap atasan. Budaya power distance kebanyakan ditimbulkan karena adanya perbedaan jabatan, kekuasaan, kemampuan finansial dikarenakan atasan memiliki kekuatan superior yang lebih tinggi dibandingkan dengan bawahan dan sering kali terjadi di perusahaan-perusahaan pada umumnya.

Hofstede (2011) menyatakan bahwa Indonesia merupakan negara yang memiliki tingkat budaya power distance tinggi. Penelitian yang dilakukan Mesmer-Magnus dan Viswesvaran (2005) menemukan bahwa semakin dekat power distance dengan pelaku kesalahan semakin besar niat untuk melakukan whistleblowing. Sementara penelitian Puni dan Anlensinya (2017) mengimpilasikan bahwa budaya power distance tinggi akan membuat karyawan tidak 
melaporkan kecurangan yang diamati, ini akan memberikan lahan subur bagi pelaku kejahatan korporasi dan tidakan tidak etis lainnya. Penelitian sebaliknya oleh Smith dan Hume (2005) membuktikan bahwa individualisme adalah penentu kuat persepsi etika di antara akuntan publik daripada power distance.

Tingginya presentase power distace di Indonesia, ditambah dengan adanya fakta bahwa korupsi, praktik korporasi yang tidak etis, dan skandal yang tidak lazim di negara ini, menyebabkan timbulnya pertanyaan praktik atau kepercayaan seperti apa yang tertanam di dalam lingkungan budaya yang mencegah seseorang ingin membongkar kegiatan tidak etis yang dilakukan atasan dalam organisasi meskipun ada Undang-Undang perlindungan bagi pengungkap kegiatan tidak etis tersebut (Hofstede, 2019). Oleh karena itu, penelitian ini mencari kecenderungan whistleblowing dalam budaya power distance dengan fokus khusus pada pengetahuan calon akuntan di Indonesia. Penelitian ini juga merefleksikan praktik budaya power distance di Indonesia dan bagaimana praktik tersebut mencegah atau menghalangi perilaku whistleblowing dalam organisasi.

Penelitian ini diharapkan dapat memberikan kontribusi untuk pengembangan teori dengan menyarankan bahwa kehadiran seorang whistleblower penting untuk kelangsungan kegiatan dalam suatu organisasi agar berjalan dengan baik tanpa ada kecurangan dengan menggunakan sikap mahasiswa. Mahasiswa akuntansi merupakan responden pada penelitian ini karena penelitian ini merupakan jenis penelitian kuasi eksperimen yang bertujuan menguji apakah terdapat perbedaan pemahaman yang relevan atas sikap yang dicobakan pada mahasiswa akuntansi dengan karyawan akuntan/auditor ketika mendapatkan perlakuan atau kasus whistleblowing. Aspek yang diteliti berhubungan dengan etika sosial, sikap, dan pemahaman perilaku whistleblowing (Diani, 2017) yang diasumsikan bahwa tidak ada perbedaan yang terlalu jauh antara mahasiswa dan praktisi akuntan/auditor. Berdasarkan uraian di atas, maka judul penelitian yang dilakukan yaitu "Pengaruh Respon Organisasi dan Power Distance terhadap Niat Melakukan Whistleblowing"

\section{REVIU LITERATUR DAN HIPOTESIS Teori Keadilan}

Teori keadilan dikemukakan oleh John Rawls, merupakan konsep keadilan tentang keharusan mendistribusikan nilai-nilai sosial dalam masyarakat secara fair atau adil agar dapat memberikan manfaat pada semua pihak yang terlibat dan berdasarkan pada kesepakatan bersama yang telah disetujui. Menurut teori ini, setiap kontribusi yang diberikan individu kepada organisasi seharusnya dibalas dengan imbalan yang proporsional agar memberikan kepuasan pada diri kontributor. Rawls mengakui bahwa untuk mewujudkan keadilan itu sulit karena dalam suatu perkumpulan manusia, kondisinya memiliki banyak perbedaan, kepentingan, kekuatan, dan pretensi dalam kehidupan bermasyarat.

Teori keadilan memiliki potensi untuk berkontribusi pada implementasi mekanisme pengaduan yang efektif karena penelitian telah menunjukkan hubungan positif antara dimensi keadilannya dan perilaku pro-sosial (Bies, Martin, \& Brockner, 1993; Cohen-Charash \& Spector, 2001 ; Colquitt, et., al, 2001; Eskew, 1993; Greenberg, 1993; Moorman, 1991; Moorman, Niehoff, \& Organ, 1993; Podsakoff \& MacKenzie, 1993; Robinson \& Morrison, 1995 dalam Seifert dan Sweeney, 2010). Karyawan meyakini bahwa mereka diperlakukan secara adil oleh atasan mereka lebih mungkin untuk membingkai hubungan sebagai pertukaran sosial timbal 
balik, memajukan perilaku yang dimaksudkan untuk mendapatkan manfaat organisasi, seperti whistleblowing (Cohen-Charash \& Spector, 2001; Moorman, 1991; Organ, 1988; Podsakoff, MacKenzie, \& Hui, 2000 dalam Seifert dan Sweeney, 2010).

Teori keadilan menyediakan kerangka kerja untuk desain mekanisme struktural yang dimaksudkan untuk meningkatkan kemungkinan whistleblowing internal. Keadilan organisasi terdiri dari tiga dimensi: keadilan distributif, prosedural, dan interaksional (Colquitt et al., 2001), dan masing-masing dimensi ini memiliki potensi untuk mempengaruhi kemungkinan pengungkapan kesalahan karyawan secara internal. Teori keadilan dikaitkan dengan penelitian ini yaitu keterkaitannya dengan variabel respon organisasi dan power distance. Pada teori ini, individu menjunjung dan mengupayakan kesamaan, kesederajatan, hak-hak, dan nilai-nilai sosial primer termasuk pendapatan, kekayaan, dan kekuasaan. Jika terdapat individu yang mengetahui adanya tindak kecurangan yang dilakukan oleh seseorang di dalam organisasinya, maka ia akan merasakan suatu ketidakadilan yang menimpa baik pada dirinya maupun kelompok. Begitupun dengan adanya tingkat respon perusahaan terhadap laporan yang telah dibuat (responsif/tidak responsif) dan juga power distance (rendah/tinggi), maka akan semakin mendorong individu tersebut untuk menegakkan keadilan karena tindak kecurangan tersebut. Sehingga individu tersebut akan semakin termotivasi untuk melakukan pelaporan tindak kecurangan atau whistleblowing.

Teori keadilan juga mengusulkan hubungan antara respon perusahaan terhadap laporan yang telah dibuat dan tindakan di masa depan oleh karyawan. Ketika karyawan percaya bahwa organisasi memperlakukan orang dengan adil dan mengambil tindakan walaupun kecurangan dilakukan oleh atasan, mereka umumnya lebih bersedia untuk terlibat dalam kegiatan untuk membantu organisasi mengidentifikasi masalah yang dapat mempengaruhi pencapaian tujuan (Rupp dan Bell, 2010).

\section{Whistleblowing}

Near dan Miceli (1985) mendefenisikan whistleblowing sebagai pengungkapan oleh anggota organisasi (mantan atau masih menjadi anggota) atas suatu praktik-praktik illegal, tidak bermoral, atau legitimasi dibawah kendali pimpinan kepada individu atau organisasi yang dapat menimbulkan efek tindakan perbaikan. Secara umum, whistleblowing didefinisikan sebagai perilaku yang ditandai dengan niat serta tindakan ketika karyawan dihadapkan dengan kesalahan atau kecurangan dalam organisasi (Bjorkelo dkk., 2010 dalam Erkmen dkk., 2014). Tindakan kecurangan dapat dilakukan oleh pegawai atau manajemen perusahaan. Seseorang yang melakukan whistleblowing disebut pelapor pelanggaran atau whistleblower. Whistleblower bisa diartikan sebagai seseorang yang berusaha mengukapkan kecurangan yang terjadi dalam suatu organisasi. Whistleblower dianggap sebagai pengkhianat karena tidak loyal terhadap organisasi, namun disisi lain juga dipandang sebagai seorang pahlawan yang melindungi kepentingan stakeholder (Zalmi, 2018).

Motif seseorang membuat laporan atau sebagai whistleblower dapat bermacam- macam, mulai dari motif itikad baik menyelamatkan organisasi, persaingan pribadi atau hal lainnya. Seseorang disebut sebagai whistleblower mempunyai dua kriteria; Pertama, whistleblower menyampaikan atau mengungkap laporan kepada otoritas yang berwenang atau kepada media massa atau publik yang diharapkan dugaan suatu kecurangan dapat diungkap dan terbongkar. 
Kedua, seorang whistleblower merupakan orang dalam yaitu orang yang mengungkap dugaan pelanggaran yang terjadi di tempatnya bekerja (Semendawai dkk, 2011).

Beberapa tahun terakhir whistleblowing sering dikaitkan dengan profesi akuntan. Profesi akuntan telah banyak terlibat dalam skandal yang terjadi di perusahaan terkhusus akuntan yang berperan sebagai auditor. Beberapa penelitian telah menjelaskan faktor-faktor yang menyebabkan akuntan /auditor memilih atau tidak memilih untuk menjadi whistleblower, faktorfaktor tersebut seperti faktor individu, faktor situasional, faktor organisasi, dan faktor demografi (Chiu, 2003; Ekmen dkk., 2014; Keenan, 2000; Darjoko dam Nahartyo, 2017; Priyastiwi, 2017; Puni dan Anlesinya, 2017; Taylor dan Curtis, 2013 dan Wong-On-Wing dan Lui, 2013)

\section{Respon Organisasi}

Taylor dan Curtis (2013) mendefinisikan respon organisasi adalah tindakkan yang dilakukan organisasi ketika menerima laporan kesalahan. Taylor dan Curtis (2013) dalam studinya menjelaskan bahwa respon organisasi hadir dalam dua kondisi, respon organisasi lemah (tidak responsif) dan respon organisasi kuat (responsif). Respon organisasi lemah (tidak responsif) mengacu pada di mana organisasi/manajemen tidak mengambil tindakan untuk menghentikan perilaku buruk dan bahkan kemudian memberikan hadiah kepada orang yang bersalah dengan kenaikan pangkat. Respon organisasi kuat (responsif) mengacu pada di mana organisasi/manajemen secara obyektif mempertimbangkan laporan yang dibuat pelapor (whistleblower) dan mengambil tindakan untuk menghentikan kegiatan kecurangan (Taylor dan Curtis, 2013). Literatur terdahulu menunjukkan kedua jenis respon organisasi menyebabkan whistleblowing berbeda tanggapan (Kayes et al., 2007).

Anggota organisasi yang melakukan whistleblowing terhadap temuan kesalahan organisasi, kemungkinan akan membuat manajemen mempertimbangkan dua jenis keputusan: apakah akan mengabaikan anggapan atau mengambil tindakan yang tepat, apakah akan memberi pengahragaan atau melakukan pemecatan terhadap pelapor (Near dan Miceli, 1985). Secara logis, respon organisasi terhadap tindakan whistleblower sebagian tergantung pada apakah manajemen setuju dengan kelayakan tuntutan dan dengan kewajiban whistleblower untuk mengambil tindakan. Dalam keadaan dimana suatu organisasi tergantung pada kesalahan yang berlanjut atau ketika mereka tidak tergantung pada whistleblower, organisasi lebih cenderung melakukan pemecatan terhadap whistleblower dan kesalahan terus dilakukan (Near dan Miceli, 1985).

Respon organisasi yang cepat dan konsisten dari manajemen akan mendeteksi dan memperbaiki perilaku yang tidak etis sebelum menjadi kebiasaan, mengurangi risiko perusahaan dan meningkatkan kenyamanan di tempat kerja secara keseluruhan (Curtis et al., 2012). Pelanggaran yang tidak terkoreksi dapat memberi sinyal kepada pengamat bahwa organisasi tidak peduli dengan perilaku yang tidak etis, dan kesalahan perilaku di masa lalu mungkin dapat mempengaruhi niat pelaporan saat ini melalui demoralisasi (Miceli et al., 2008). Respons manajemen yang positif, yang mencakup tindakan untuk menghentikan perilaku yang tidak etis, diperkirakan akan dikaitkan dengan peningkatan kemungkinan pengaduan (Finn, 1995).

\section{Power Distance}

Power distance dapat didefinisikan sebagai ukuran relatif dari jarak dalam posisi antara dua pihak - dalam kasus ini, antara pengamat dan pelaku kesalahan (Taylor dan Curtis, 2013). Sedangkan Rao dan Pearce (2016) menjelaskan power distance adalah sejauh mana individu 
menerima perbedaan dalam peringkat, status, hak istimewa dan kekuasaan dalam masyarakat. Power distance adalah salah satu variabel yang mengilustrasikan keterkaitan budaya dan hubungan sebab akibat karena adanya disparitas kekuatan yang membedakan manusia dalam jabatan di suatu organisasi (Farh et al., 2007).

Taylor dan Curtis (2013) dalam penelitiannya menjelaskan bahwa power distance memiliki dua bentuk, power distance rendah dan power distance tinggi. Power distance rendah menunjukkan adanya kesetaraan antara atasan-bawahan dalam kekuasaan, tidak menerima perbedaan jabatan, dan tidak takut mengahadapi atasan. Power distance tinggi menunjukkan perbedaan secara luas antara atasan-bawahan serta memberikan penghormatan kepada atasan secara besar.

Power distance membawa implikasi etis yang penting (Goodwin, 1999). Power distance yang tinggi dapat menyebabkan seseorang tidak mau menantang perilaku tidak etis dari atasan, sementara power distance yang rendah kemungkinan akan mendorong individu untuk menantang perilaku yang tidak etis tersebut dengan whistleblowing (Curtis et al., 2012). Puni dan Anlensinya (2017) menemukan bahwa power distance tinggi meningkatkan persepsi negatif terhadap whistleblowing dan menganggap bahwa whistleblower sebagai pengkhianat bukan pahlawan.

Karyawan cenderung untuk melaporkan rekan mereka daripada atasan mereka, karena rekan kerja tidak cukup untuk menekan untuk menjadi whistleblowing (Taylor dan Curtis, 2013). Laporan tentang perilaku tidak etis yang dilakukan oleh whistleblower merupakan pengaruh dari tekanan kepatuhan yang diperoleh ketika orang yang berbuat salah adalah atasan (Deloitte \& Touche, 2007). Penelitian tentang pengaruh terkait power distance atas whistleblower ada beberapa bukti awal menunjukkan bahwa pada power distance rendah lebih mungkin daripada power distance tinggi untuk melakukan whistleblowing (Taylor dan Curtis, 2013).

\section{Hubungan Respon Organisasi terhadap Whistleblowing}

Teori keadilan merupakan konsep keadilan tentang keharusan mendistribusikan nilai-nilai sosial dalam masyarakat secara fair atau adil agar dapat memberikan manfaat pada semua pihak yang terlibat dan berdasarkan pada kesepakatan bersama yang telah disetujui (Rawl, 2001). Adanya skandal keuangan di perusahaan menyebabkan munculnya niat seseorang untuk melakukan whistleblowing, karena whistleblowing memegang peran penting untuk mengukapkan skandal tersebut. Semakin besar minat seseorang untuk membantu mengungkap tindakan kecurangan yang ia temukan dalam organisasi maka akan semakin sedikit kerugian yang dirasakan oleh masyarakat secara umum. Untuk mengambil keputusan dalam melaporkan tindak kecurangan yang terjadi di suatu organisasi, whistleblower memiliki berbagai faktor yang menjadi bahan pertimbangan untuk menjadi whistleblower salah satunya adalah faktor organisasi dan faktor budaya.

Faktor organisasi yang diduga mempengaruhi niat seseorang untuk melakukan whistleblowing adalah respon organisasi. Respon organisasi merupakan tindakan yang diambil oleh manajemen organisasi ketika menerima laporan. Ketika manajemen mengambil tindakan dengan cara menghentikan pelaku kecurangan, maka manajemen dikatakan responsif. Sebaliknya, jika manajemen memberikan hadiah berupa kenaikan jabatan atau manajemen tidak melakukan tindakan apapun maka manajemen disebut tidak responsif (Taylor dan Curtis, 2013). 
Teori keadilan menjelaskan bahwa setiap kontribusi yang diberikan individu kepada organisasi dibalas dengan imbalan yang proporsional dapat memberikan kepuasan pada diri kontributor sehingga meningkatkan keinginan seseorang melakukan tindakan whistleblowing (Seifert et al. 2010). Ketika karyawan percaya bahwa organisasi memperlakukan orang dengan adil, mereka umumnya lebih bersedia untuk terlibat dalam kegiatan untuk membantu organisasi mengidentifikasi masalah yang dapat mempengaruhi pencapaian tujuan organisasi (Rupp dan Bell 2010). Sebaliknya, ketika organisasi dianggap tidak adil karyawan mungkin kurang bersedia melaporkankecurangan karena adanya karena kekhawatiran bahwa organisasi yang tidak adil tidak akan mengambil langkah-langkah untuk melindungi pelaku kecurangan dari tindakan pembalasan. Perjelasan tersebut mengarah pada hipotesis pertama:

H1: Individu yang berada di lingkungan respon organisasi kuat akan lebih cenderung menunjukkan niat melakukan whistleblowing dibandingkan individu yang berada di lingkungan respon organisasi lemah.

\section{Hubungan Power Distance terhadap Whistleblowing}

Faktor budaya yang diduga mempengaruhi niat seseorang melakukan whistleblowing adalah power distance. Power distance mempengaruhi seseorang menjadi whistleblower karena budaya power distance tinggi menyebabkan karyawan tidak dapat menantang atau mempertanyakan tindakan dan keputusan dari atasan mereka (Puni dan Anlensinya, 2017) Lingkungan dengan power distance rendah, akan memandang bahwa kekuasaan terdistribusi secara merata sehingga rendahnya tekanan sosial dalam organisasi yang dapat meningkatkan whistleblowing. Sedangakan, lingkungan yang memiliki power distance tinggi, adanya hubungan kekuasaan yang lebih autokratik dan paternalistik.

Literatur akuntansi menjelaskan bahwa terdapat beberapa tipe dalam tekanan pengaruh sosial yang mempengaruhi professional judgement dan perilaku auditor/akuntan, yaitu; compliance pressure yang menyebabkan seseorang melakukan apa yang diperintahkan terlepas dari tingkat permohonan, obedience pressure yang mempengaruhi seseorang untuk tunduk kepada otoritas, dan conformiy (peer) pressure yang menghasilkan keinginan untuk berpikir dan berperilaku konsisten dengan anggota grup.

Obedience pressure mungkin mempengaruhi pelaporan ketika pelaku kesalahan adalah atasan. Finn (1995) dalam Taylor dan Curtis (2013) membahas power distance dalam whistleblowing, menjelaskan bahwa power distance memberi kesan bahwa risiko atas retaliation (pembalasan, termasuk kehilangan pekerjaaan) adalah yang terbesar jika melaporkan atasan sebagai pelaku kesalahan, dan hal tersebut mengurangi kecenderungan untuk whistleblowing.

Teori keadilan mendistribusikan nilai-nilai sosial di lingkungan secara fair atau adil agar dapat memberikan manfaat pada semua pihak yang terlibat. Sebuah studi komprehensif tentang perilaku whistleblower yang dilakukan oleh Mesmer-Magnus dan Viswesvaran (2005) menemukan bahwa semakin dekat potensi whistleblower dengan pelaku kesalahan (baik secara interpersonal atau sehubungan dengan struktur organisasi), semakin besar niatnya untuk melakukan whistleblowing atas pelanggaran yang diamati. Perjelasan tersebut mengarah pada hipotesis kedua:

H2: Individu yang berada di lingkungan budaya power distance rendah akan lebih cenderung menunjukkan niat melakukan whistleblowing dibandingkan individu yang berada di lingkungan budaya power distance tinggi. 


\section{METODE PENELITIAN}

Penelitian ini menggunakan data kuantitatif. Jenis data yang diperoleh dari penelitian ini merupakan jenis data subjek. Data subjek (self report data) adalah data penelitian yang dilaporkan sendiri oleh responden secara individual atau kelompok berupa sikap, opini, pengalaman/karakteristik. Sumber data yang digunakan dalam penelitian ini adalah data primer. Data primer merupakan data yang diperoleh langsung dari sumber pertama seperti perorangan atau individu.

Penelitian ini menggunakan mahasiswa jurusan akuntansi Strata I di Fakultas Ekonomi Universitas Negeri Padang angkatan 2017 sebagai partisiapan. Teknik pengambilan sampel yang digunakan dalam penelitian ini adalah purposive sampling. Berikut kriteria yang ditentukan dalam purposive sampling: Mahasiswa yang dipilih hanya angkatan tahun 2017 di Universitas Negeri Padang, karena angkatan tahun tersebut sedang mengikuti proses perkuliahan. Mahasiswa akuntansi yang menjalankan kuliah pada jenjang S1, karena jenjang S1 merupakan tingkat pendidikan yang siap memasuki dunia kerja, dan diasumsikan akan menjadi calon staf akuntan/auditor baik di perusahaan atau sektor publik. Mahasiswa akuntansi yang sudah lulus mata kuliah etiak bisnis dan profesi, akuntansi sektor publik, akuntansi manajemen, dan auditing, sehingga dapat diasumsikan bahwa mahasiswa sudah mengetahui dan memiliki pemahaman yang baik mengenai akuntansi, serta masalah pengauditan.

\section{Desain Penlitian}

Penelitian ini bertujuan untuk melihat seberapa jauh pengaruh variabel bebas mempengaruhi variabel terikat. Penelitian ini menggunakan pendekatan kuantitatif, dan tergolong jenis penelitian kausatif, serta menggunakan data primer yang dikumpulkan dengan desain penelitian kuasi eksperimen. Sugiyono (2013) menjelaskan kuasi eksperimen merupakan pengembangan true experiment design yang sulit dilaksanakan dalam menentukan kelompok kontrol dalam penelitian. Desain kuasi eksperimen adalah desain yang mempunyai kelompok kontrol tetapi tidak dapat berfungsi secara penuh untuk mengontrol variabel-variabel luar (extraneous variables) yang dapat mempengaruhi pelaksanaan kuasi eksperimen (Sugiyono, 2013; Cooper dan Schindler, 2014). Kuasi eksperimen (eksperimen semu) menggunakan seluruh subjek dalam kelompok belajar (Intact group) untuk diberi perlakuan (treatment), bukan memakai pengambilan subjek acak (Cooper dan Schindler, 2014).

Desain kuasi eksperimen yang digunakan dalam penelitian ini adalah desain faktorial $2 \times 2$. Variabel independen terdiri dari respon organisasi dan power distance. Variabel respon organisasi dimanipulasi menjadi respon organisasi lemah dan respon organisasi kuat. Sedangkan variabel power distance dimanipulasi menajdi power distance rendah dan power disatnce tinggi.

\section{Instrumen Penelitian}

Instrumen pada penelitian ini diadopsi dari Taylor dan Curtis (2013). Sebelum menggunakan instrumen ini, peneliti terlebih dahulu menerjemahkan instrumen tersebut dari Bahasa Inggris ke Bahasa Indonesia. Setelah instrumen diterjemahkan, peneliti meminta pendapat beberapa teman mengenai instrumen penelitian yang sudah diterjemahkan tersebut. Kemudian memodifikasi instrumen tersebut dengan merubah ilustrasinya sesuai kebutuhan.

Instrumen penelitian ini terdiri dari empat versi, semua versi dari kasus ini dimulai dengan deskripsi dari kantor audit terkait dengan kebijakan whistleblower yang jelas dan 
mendorong karyawan untuk melaporkan kesalahan yang diamati. Kuesioner tersebut mengilustrasikan bahwa di KAP terkait mempunyai kebijakan bahwa karyawan dapat melaporkan pelanggaran/kecurangangan/perilaku tidak etis yang diamati yang melanggar kode etik kepada seseorang yang berwenang di organisasi atau melalui hotline karyawan perusahaan.

Skenario versi pertama menggambarkan organisasi yang responsif. Skenario versi kedua menggambarkan organisasi yang tidak responsif.

Responsif: Anda telah mengamati bahwa, bahwa ketika karyawan membuat laporan tentang pelanggaran etika pihak berwenang di organisasi menegur dan menasehati pelanggar tersebut atau mengambil tindakan yang sesuai.

Tidak responsif: Anda telah mengamati bahwa, bahwa ketika karyawan membuat laporan tentang pelanggaran etika pihak berwenang di organisasi tidak mengambil tindakan apapun yang sesuai dengan pelanggaran dan bahkan memberikan kesempatan bagi para pelanggar untuk naik jabatan di dalam perusahaan.

Skenario ketiga dan keempat menggambarkan pelanggaran terhadap standar profesional. Peneliti memanipulasi jarak dengan peran sebagai 'penanggung jawab' (rekan) atau 'manajer'(superior).

Anda sesang melakukan wawancara audit dengan asisten pengawas keuangan PT. ABC, Anda terkejut ketika mengetahui bahwa manajer [rekan sejawat] Anda, Atta, telah menerima tawaran jabatan baru sebagai pengawas keuangan pada PT. ABC. Disamping itu, manajer [rekan sejawat] Anda masih melanjutkan tugasnya mengaudit pada PT. ABC.

\section{Cek Manipulasi}

Pengecekan manipulasi untuk respon organisasi dilakukan dengan mengajukan pertanyaan : "Apakah tampaknya KAP menginvestigasi dan mengambil tindakan yang sesuai terhadap pelanggar ketika laporan dibuat?". Pengecekan manipulasi power distance dengan pertanyaan “Apakah kasus ini berkaitan dengan manajer atau rekan sejawat?". Responden dikatakan lulus uji manipulasi apabila merespon sesuai dengan kasus yang telah diberikan dengan mencentang salah satu pilihan.

Untuk menghindari terjadinya bias pada permasalahan data, sudut pandang/perspektif orang pertama digunakan dalam ilustrasi yang disajikan. Sudut pandang orang pertama digunakan karena akan menjadikan responden sebagai tokoh dalam skenario dan responden juga akan merasa melakukan setiap ilustrasi yang dibuat (Salamadian, 2017).

\section{HASIL DAN PEMBAHASAN \\ Hasil}

\section{Karakteristik Partisipan}

Berdasarkan hasil penelitian yang dilaksanakan, diketahui bahwa berikut ini merupakan karakteristik responden yang menjadi sampel dalam penelitian ini. Karakteristik responden dirangkum dalam Tabel 1 dibawah ini yang disajikan secara umum berdasarkan jenis kelamin, umur, agama dan suku. 
Tabel 1

Karakteristk Demografi

\begin{tabular}{|c|l|c|c|}
\hline Data & \multicolumn{1}{|c|}{ Level } & Frekuensi & $\%$ \\
\hline \multirow{3}{*}{ Jenis Kelamin } & Laki-laki & 22 & $40,74 \%$ \\
\cline { 2 - 4 } & Perempuan & 32 & $59,26 \%$ \\
\hline \multirow{3}{*}{ Agamar } & 20 & 18 & $33,33 \%$ \\
\cline { 2 - 4 } & 21 & 30 & $55,56 \%$ \\
\cline { 2 - 4 } & 22 & 6 & $11,11 \%$ \\
\hline \multirow{5}{*}{ Suku } & Islam & 53 & $98,15 \%$ \\
\cline { 2 - 4 } & Katolik & 1 & $1,85 \%$ \\
\hline & Aceh & 1 & $1,85 \%$ \\
\cline { 2 - 4 } & Batak & 1 & $1,85 \%$ \\
\cline { 2 - 4 } & Jawa & 5 & $9,26 \%$ \\
\cline { 2 - 4 } & Melayu & 2 & $3,70 \%$ \\
\cline { 2 - 4 } & Minang & 45 & $83,33 \%$ \\
\hline
\end{tabular}

Sumber : Data primer yang diolah, 2020

Berdasarkan Tabel 1 di atas dapat diketahui bahwa lebih dari setengah sampel adalah wanita. Para responden dengan rata-rata umur di atas 20 tahun menunjukkan bahwa mereka dikatakan sudah bisa mengambil tindakan dan menentukan keputusan ketika melihat sesuatu yang salah. Kemudian hampir 100\% dari responden beragana Islam. Sekitar tujuperdelapan dari sampel bersuku Minang.

Tabel 2

Analisis Demografi Partisipan

\begin{tabular}{|l|r|r|r|r|}
\hline \multicolumn{5}{|c|}{ Hasil Uji ANOVA } \\
\hline \multicolumn{5}{|c|}{ Variabel Dependen: Niat Melakukan Whistleblowing } \\
\hline & \multicolumn{1}{|c|}{ SS } & \multicolumn{1}{|c|}{ df } & \multicolumn{1}{c|}{ F } & \multicolumn{1}{c|}{ Sig. } \\
\hline Jenis Kelamin & 0,545 & 1 & 0,111 & 0,740 \\
\hline Umur & 13,089 & 2 & 6,544 & 0,262 \\
\hline Agama & 1,811 & 1 & 0,371 & 0,545 \\
\hline Suku & 6,300 & 4 & 1,575 & 0,871 \\
\hline
\end{tabular}

Sumber : Data primer yang diolah, 2020

Tabel 2 merupakan hasil analisis demografi partisipan yang bertujuan untuk melihat apakah ada pengaruh antara variabel demografi terhadap niat melakukan whistleblowing. Data demografi tersebut kemudian diuji dengan ANOVA. Dari hasil uji tersebut diperoleh bahwa keempat variabel demografi yaitu, jenis kelamin, umur, agama dan suku tidak berpengaruh secara statistik terhadap niat melakukan whistleblowing. Hal tersebut dapat dilihat dari nilai signifikansi yang lebih dari $0,05(p>0,05)$. 


\section{Analisis Deskriptif}

Analisis deskriptif pada penelitian ini menunjukkan gambaran mengenai suatu data yang dilihat dari nilai rata-rata (mean) daan standar deviasi setiap variabel yang diteliti.

Tabel 3

Analisis Deskriptif

\begin{tabular}{|c|c|c|c|}
\hline Power & Kuat (B1) & Lemah (B2) & \\
\hline Tinggi (A1) & $\begin{array}{l}\mathrm{n}=14 \\
\bar{x}=12,21 \\
\sigma=18,58\end{array}$ & $\begin{aligned} \mathrm{n} & =14 \\
\bar{x} & =18,71 \\
\sigma & =22,66\end{aligned}$ & $\begin{array}{c}\mathrm{n}=28 \\
\bar{x}=30,92 \\
\sigma=41,24\end{array}$ \\
\hline Rendah (A2) & $\begin{array}{c}\mathrm{n}=13 \\
\bar{x}=42,92 \\
\sigma=23,11\end{array}$ & $\begin{array}{c}\mathrm{n}=13 \\
\bar{x}=34,54 \\
\sigma=24,94\end{array}$ & $\begin{array}{c}\mathrm{n}=26 \\
\bar{x}=77,46 \\
\sigma=48,05\end{array}$ \\
\hline & $\begin{array}{c}\mathrm{n}=27 \\
\bar{x}=55,13 \\
\sigma=41,69\end{array}$ & $\begin{array}{c}\mathrm{n}=27 \\
\bar{x}=53,25 \\
\sigma=47,60\end{array}$ & \\
\hline
\end{tabular}

Sumber: Data primer yang diolah, 2020

Sel 1 (A1B1) menunjukkan niat melakukan whistleblowing dengan rata-rata 12,21 (deviasi standar 18,58) dibandingkan dengan niat melakukan whistleblowing pada sel 4 (A2B2) yang memiliki rata-rata 34,54 (deviasi standar 24,94). Sebelum diuji lebih lanjut dengan ANOVA, hasil pada tabel 3 mengindikasikan bahwa lingkungan organisasi dengan power distance rendah disertai dengan respon organisasi kuat akan menimbulkan niat seseorang untuk melakukan whistleblowing. Efek utama dari power distance juga diindikasi dengan nilai gabungan sel 3 dan 4 yang lebih besar daripada nilai gabungan sel 1 dan 2 (hasilnya 77,46 dibandingkan dengan 30,92). Sementara itu, efek utama respon organisasi ditunjukkan dengan nilai gabungan sel 1 dan 3 yang lebih besar daripada nilai gabungan sel 2 dan 4 (hasilnya 55,13 dibandingkan dengan $53,25)$.

\section{Hasil Uji Hipotesis}

\section{Tabel 4}

Levene's Test of Equality of Error Variances

Dependent Variable:Niat Melakukan Whistleblowing

\begin{tabular}{|c|c|c|c|}
\hline $\mathrm{F}$ & $\mathrm{df} 1$ & $\mathrm{df} 2$ & Sig. \\
\hline 1,680 & 3 & 50 & 0,183 \\
\hline
\end{tabular}

Sumber : Data primer yang diolah, 2020 
Tabel 4 digunakan untuk menguji hipotesis nol yang menyatakan bahwa variance dari grup dalam penelitian ini adalah sama (merupakan asumsi dari ANOVA). Jadi dalam hal ini tabel 4 menguji apakah variance dari ke empat skenario manipulasi secara sigifikan berbeda. Hasil nilai $\mathrm{F}$ sebesar 1,680 dengan signifikansi 0,183 yang jauh di atas $0,05(p>0,05)$. Sehingga dapat disimpulkan bahwa tidak dapat menolak hipotesis nol (tidak signifikan) atau dengan kata lain variance dari ke empat skenario manipulasi adalah sama (memenuhi asumsi ANOVA).

\section{Tabel 5}

Hasil Uji Hipotesis

\begin{tabular}{|l|r|r|r|r|r|}
\hline Source & $\begin{array}{r}\text { Type III Sum of } \\
\text { Squares }\end{array}$ & df & Mean Square & \multicolumn{1}{|c|}{ F } & Sig. \\
\hline Corrected & 8050,632 & 3 & 2683,544 & 5,358 & 0,003 \\
Model & 39596,513 & 1 & 39596,513 & 79,056 & 0,000 \\
Intercept & 11,971 & 1 & 11,971 & 0,024 & 0,878 \\
RO & 7297,920 & 1 & 7297,920 & 14,571 & 0,000 \\
PD & 746,712 & 1 & 746,712 & 1,491 & 0,228 \\
RO * PD & 25043,368 & 50 & 500,867 & & \\
Error & 71494,000 & 54 & & & \\
Total & 33094,000 & 53 & & & \\
Corrected & & & & \\
Total & & & & \\
\hline
\end{tabular}

Sumber: Data primer yang diolah, 2020

Tabel 5 menggambarkan pengaruh keseluruhan dari eksperimen. Pada kolom source, sum of squares dari model sebesar (SSm $=11,971$ dan 7297,920) sedangkan mean square sebesar 11,971 dan 7297,920. Sum of square dari model menggambarkan total pengaruh eksperimen sedangkan mean square dari model menggambarkan rata-rata pengaruh eksperimen. Pada source error (within-group) memberikan detail variasi unsystematic dari data. Besarnya residual sum of square (SSr ) adalah 25043,368 dan besarnya residual mean square (MSr) adalah 500,867. Pengujian apakah nilai rata-rata whistleblowing antar variabel sama dengan menggunakan nilai rasio $\mathrm{F}$ untuk kombinasi between-group effect.

Dari hasil pengujian ANOVA di atas dapat dilihat bahwa nilai signifikansi untuk variabel respon organisasi adalah 0,878 lebih dari 0,05 $(p>0,05)$. Hal ini menunjukkan bahwa hipotesis pertama ditolak, artinya individu yang berada di lingkungan respon organisasi kuat tidak akan menunjukkan niat melakukan whistleblowing dibandingkan individu yang berada di lingkungan respon organisasi lemah. Sedangkan hipotestis kedua diterima, hal ini terlihat dari nilai signifikansi power distance adalah 0,000 kurang dari $0,05(p<0,05)$. Individu yang berada di lingkungan budaya power distance rendah akan lebih cenderung menunjukkan niat melakukan whistleblowing dibandingkan individu yang berada di lingkungan budaya power distance tinggi.

\section{Pembahasan}

\section{Perbedaan Pengaruh Respon Organisasi Terhadap Niat Melakukan Whistleblowing}

Hasil pengujian hipotesis menunjukkan tidak ada perbedaan pengaruh respon organisasi kuat dan respon organisasi lemah terhadap niat melakukan whistleblowing. Hal ini dapat dilihat dari hasil 
pengolahan data menggunakan uji one way ANOVA. Hasil tabel menunjukkan F hitung sebesar 0,024 dan diperkuat dengan nilai signifikans yang diperoleh sebesar 0,878>0,05.

Respon organisasi diduga akan berpengaruh positif terhadap niat melakukan whistleblowing karena ketika organisasi/manajer mengambil tindakkan dari laporan kecurangan yang telah dibuat karyawan, maka karyawan akan merasakan bahwa setiap kontribusi yang diberikan kepada organisasi dibalas dengan imbalan yang proporsional dan dapat memberikan kepuasan pada diri kontributor sehingga meningkatkan keinginan seseorang melakukan tindakan whistleblowing. Penelitian ini tidak menemukan efek utama dari respon organisasi, hal ini menandakan bahwa respon yang tidak tepat dari suatu organisasi terhadap satu masalah dapat berdampak pada individu lain dan juga akan berdampak pada permasalahan lainnya.

Teori keadilan menjelaskan bahwa setiap kontribusi yang diberikan individu kepada organisasi dibalas dengan imbalan yang proporsional dapat memberikan kepuasan pada diri kontributor sehingga meningkatkan keinginan seseorang melakukan tindakan whistleblowing (Seifert et al. 2010). Penelitian mengenai respon organisasi terhadap whistleblowing telah dilakuakan oleh beberapa peneliti terdahulu. Hasil penelitian ini konsisten dengan hasil penelitian yang telah dilakukan Taylor dan Curtis (2013) dan Miceli et al. (2008) yang menyatakan bahwa tidak ada efek utama respon organisasi terhadap niat melakukan whistleblowing untuk melaporkan perilaku buruk atau kecurangan yang diamati.

Meskipun penelitian ini tidak menemukan efek utama dari respon organisasi, penelitian sebelumnya yang dilakukan oleh Miceli et al. (2008) menunjukkan bahwa ada biaya lain bagi organisasi untuk persepsi (benar atau salah) sehingga menyebabkan organisasi tidak menanggapi laporan perilaku tidak etis di luar pengaruhnya terhadap pelaporan. Miceli et al. (2008) menyarankan bahwa ketika karyawan mempersepsikan keengganan untuk menanggapi laporan, dua biaya terjadi. Pertama, sumber daya yang didedikasikan untuk hotline dan berbagai proses serta program pelatihannya mungkin terbuang. Kedua, demoralisasi dari pengamatan, kesalahan yang tidak terkoreksi dapat menciptakan biaya lain, seperti moral karyawan yang buruk dan tindakan karyawan yang tidak berfungsi.

\section{Perbedaan Pengaruh Power Distance Terhadap Niat Melakukan Whistleblowing}

Hasil dari pengujian hipotesis kedua menunjukkan bahwa individu pada budaya power distance rendah akan menunjukkan niat melakukan whistleblowing yang berbeda dibandingkan dengan individu yang berada pada buadaya power distance tinggi. Hal ini dapat dilihat dari hasil pengolahan data menggunakan uji one way ANOVA. Hasil tabel menunjukkan F hitung sebesar 14,571 sedangkan nilai signifikansi diperoleh sebesar $0,000<0,05$.

Hasil penelitian ini memberikan kesimpulan bahwa individu yang berada di budaya power distance rendah dianggap lebih memiliki keberanian atau suka terhadap tantangan ketika melihat suatu temuan kesalahan dibandingkan power distance tinggi yang memikirkan risiko yang akan dihadapinya dalam lingkungan pekerjaan. Karyawan lebih bersedia melaporkan rekan kerja mereka, karena tekanan dari teman sebaya tidak cukup untuk menekan perilaku whistleblowing. Namun, seperti diteorikan power distance tinggi yang ada di perusahaan tampaknya menghasilkan tekanan kepatuhan, dibuktikan dengan adanya keengganan karyawan untuk melaporkan atasan. Karyawan lebih sering berinteraksi dengan manajer daripada mitra karena itu karyawan bisa mengamati perilaku yang dilakukan manajer (perilaku buruk) yang dapat mengancam kualitas perusahaan. 
Keengganan umum untuk melaporkan atasan karena teori level konstrual (ide bahwa penilaian seseorang atas suatu tindakan bergantung pada jarak psikologis [mis., sosial atau temporal] antara mereka dan orang yang melakukan tindakan) dapat memberikan penjelasan. Jadi, jika seorang kolega bertingkah buruk, kedekatan psikologisnya mungkin menurun sehingga terjjadi bias penilaian pengamat atas keseriusan tindakan tersebut.

Sejalan dengan penelitian Taylor dan Curtis (2013), Puni dan Anlesinya (2017) dan Wong-On Wing dan Lui (2013) bahwa budaya power distance mempengaruhi keputusan untuk melakukan whistleblowing. Budaya yang kekuasaannya terdistrbusi secara tidak merata membuat hierarki kekuasaan mengerucut sehingga pada lapisan paling bawah merasa ada tekanan ketika hendak melaporkan atasan. Karyawan yang hanya memiliki tujuan untuk memenuhi standar profesional secara teknis dengan melaporkan kecurangan yang dilihatnya, tetapi takut untuk melaporkan kecurangan tersebut karena pelakuknya adalah manajer/atasan, dapat mengurangi kemungkinan pengaduan pada sutau organisasi yang responsif. Oleh sebab itu, perusahaan dapat membentuk budaya organisasi yang tidak mencermikan adanya jarak kekuasan dan perusahaan memicu karyawan untuk ikut berpasrtisipasi mewujudkan organisasi yang bebas dari tindak kecurangan melalui tindakan whistleblowing.

\section{KESIMPULAN, KETERBATASAN DAN SARAN Kesimpulan}

Berdasarkan hasil temuan penelitian dan pengujian hipotesis yang telah dilakukan dapat disimpulkan bahwa individu yang berada pada budaya power distance rendah akan menunjukkan niat melakukan whistleblowing yang berbeda dengan individu yang berada pada budaya power distance tinggi.

\section{Keterbatasan}

Selama proses pelaksanaan penelitian ini, peneliti menyadari masih terdapat banyak keterbatasan. Keterbatasan tersebut berkemungkinan memberikan gangguan pada hasil dalam penelitian ini. Penelitian kuasi eksperimen ini menggunakan skenario sebagai ilustrasi dalam dunia nyata yang disebarkan melalui kuesioner kepada mahasiswa. Penyebaran kuesioner kepada mahasiswa tersebut menyebabkan hasil penelitian ini tidak dapat digeneralisasikan untuk setiap kondisi. Skenario tersebut juga terbatas karena mengandung bias yang tidak bisa sepenuhnya sesuai dengan kondisi di lapangan.

Penggunaan mahasiswa sebagai responden dalam penelitian ini menyebabkan sebagian kecil kurang memahami prosedur penelitian yang dijelaskan melalui sugesti perlakuan/treatment yang peneliti berikan, sehingga sebagian kecil tidak lolos uji manipulasi. Penyebaran kuesioner dalam penelitian ini dilakukan secara online sehingga menyebabkan kuesioner yang disebarkan ke responden tidak kembali ke peneliti seluruhnya, bahkan kuesioner yang tidak kembali tersebut sebanyak seperempat dari jumlah responden.

\section{Saran}

Keterbatasan yang ada dalam penelitian ini membutuhkan beberapa perbaikan, supaya peneliti dimasa yang akan datang diharapkan dapat memberikan hasil yang lebih baik. Beberapa saran yaitu: memberikan treatment/perlakuan terhadap responden kuasi eksperimen secara lebih baik dan merancang prosedur yang efektif sehingga memicu responden dalam mengerjakan kuesioner 
serta responden dapat memahami dengan baik treatment/perlakuan yang diberikan dan lolos uji manipulasi. Menggunakan sampel yang lebih besar misalkan karyawan dalam perusahaan atau auditor internal maupun auditor eksternal. Menggunakan variabel independen lain yang mungkin memiliki pengaruh terhadap niat melakukan whistleblowing seperti intensitas moral, tekanan ketaatan, kepercayaan kepada pemimpin, penalaran moral, konflik peran, tingkat keseriusan kesalahan, dan komunikasi interpersonal organisasi.

\section{DAFTAR PUSTAKA}

Ahmad, S. A., Smith, M., Ismail, Z., \& Yunos, R. M. (2011). Internal whistleblowing intentions: Influence of internal auditors' demographic and individual factors. Annual Summit on Business and Entrepreneurial Studies (ASBES 2011) Proceeding.

Chiu, Randy K. (2003). Ethical judgement and whistleblowing intention: Examining the moderating role of locus of control. Journal of business ethics, 43, 65-74.

Colquitt, J., Wesson, M., Porter, C., Conlon, D., \& Ng, K. (2001). Justice at the millennium: A meta-analytic review of 25 years of organizational justice research. Journal of Applied Psychology, 86, 425-445.

Cooper, D. R., dan Pamela S. S. (2014). Business Research Methods. Twelfth Edition. Florida Atlantic University: McGraw-Hill Companies, inc.

Curtis, et al. (2012). A cross-cultural study of the inflfluence of country of origin, justice, power distance, and gender on ethical decision making. Journal of International Accounting Research, 11 (1), 5-34.

Darjoko, F. J., \& Nahartyo, E. (2017). Efek tipe kecurangan dan anonimitas terhadap keputusan investigasi auditor internal atas tuduhan whistleblowing. Jurnal Akuntansi dan Keuangan Indonesia, 14(2), 202-221.

Diani, R. C dan Narsa, I . (2017). Moral reasoning level and role conflict: Experimental study for whistleblowing behavior model internal government.

Erkmen, Turhan dan Emel E. (2014). Work family, family work conflict and turnover intentions among the representatives of insurance agencies. Journal of Business, Economics and Finance, 3 (3), 302-312.

Fajri, P dkk. (2017). Pengaruh tingkat keseriusan pelanggaran, faktor demografi dan faktor organisasional terhadap intensi whistleblowing. Kajian Akuntansi, 18, 124-132

Farh, J. R., D., et,. al. (2007). Individual-level cultural values as moderators of perceived organizational support-Employee outcome relationships in China: Comparing the effects of power distance and traditionality. Academy of Management Journal, 50 (3): 715-729.

Finandari, D dan Titis W. (2016). Analisis pengaruh dimensi budaya terhadap niat melakukan whistleblowing perbandingan antara mahasiswa dan engineer. Jurnal Teknosains, 6(1), 44-52.

Finn, D. W. (1995). Ethical decision making in organizations: A management employeeorganization whistleblowing model. Research on Accounting Ethics. 1, 291-313.

Hofstede, G. H. (2001). Culture's consequences: Comparing values, behaviors, institutions, and organizations across Nations. Thousand Oaks, CA: Sage Publications.

Hofstede, G. H. (2011). Dimensionalizing cultures: The hofstede model in context. Online Readings in Psychology and Culture, 2(1) at http://dx.doi.org/10.9707/23070919.1014 
http://birokratmenulis.org/. "Dilematika whistleblower birokrat: Pahlawan atau Pengkhianat". Accessed on date February 20, 2020.

http://www.bumn.go.id/. "Kementerian BUMN luncurkan aplikasi whistleblowing system. Accessed on date January 15, 2020.

http://www.deloitte.com. "Leadership counts". Accessed on date January 15, 2020.

https://m.cnnindonesia.com. "Kronologi kasus jiwasraya, gagal bayar hingga dugaan korupsi". Accessed on date February 20, 2020.

https://www.hofstede-insights.com/. "Country comparison". Accessed on date November 1, 2019.

https://www.ojk.go.id/. "Siaran Pers: Relaunching OJK Whistleblowing system 2015 tahun penguatan integritas OJK". Accessed on date January 16, 2020.

https://www.salamadian.com. "Pengertian Sudut Pandang: Jenis, Macam, dan Contoh". Accessed on date March 8, 2020.

Kayes, D. C., D. Stirling, and T. M. Nielsen. (2007). Building organizational integrity. Business Horizon, 50, 61-70.

Keenan. (2000). Blowing the wistle on less serious form of fraud: A study of executives and managers. Employee Responsibilities and Rights Journal, 12(4), 199-217

Mesmer J., and C. Viswesvaran. (2005). Whistleblowing in organizations: An examination of correlates of whistleblowing intentions, actions, and retaliation. Journal of Business Ethics. 62 (3), 277-297.

Miceli, M. P., J. P. Near, and T. M. Dworkin. (2008). Whistle-Blowing in organizations. New York, NY: Routledge.

Napitupulu, Beatrice dan Bernawati. (2016). Pengaruh faktor organisasional, faktor individual, dan faktor demografi terhadap intensi whistleblowing. Surabaya: e-Journal Universitas Airlangga.

Near, J.P. dan Miceli, M. P. (1985). Organizational dissidence: The case of whistleblowing. Journal of business ethics, 4, 1-16.

Parmerlee, Marcia A et al. (1982). Correlations of whistleblowers' perceptions of organizational retaliation. Adminitrative Science Quarterly, 27(1) 17-34.

Priyastiwi. dan Halim (2017). Pengaruh Faktor Demografi Dan Iklim Organisasi Terhadap Niat Whistleblowing Internal. Jurnal Riset Manajemen, 4 (1): 12-22.

Puni, A dan Anlesinya, A. (2017). Whistleblowing Propensity in Power Distance Societies. Journal of Global Responsibility, 29.

Rupp, D. E., and C. M. Bell. (2010). Extending the deontic model of justice: Moral selfregulation in thirdparty responses to injustice. Business Ethics Quarterly. 20 (1): 89-106.

Seifert, D. L., J. T. Sweeney, J. A. Joireman, and J. M. Thornton. (2010). The inflfluence of organizational justice on accountant whistleblowing. Accounting, Organizations and Society, 35: 707-717.

Semendawai, Abdul Haris dkk. (2011). Memahami Whistleblower. Lembaga Perlindungan Saksi dan Korban (LPSK). Diakses pada 22 Januari 2020 dari www.lpsk.go.id.

Sims, R. L dan Keenan, J. P. (1998). Predictors of external whistleblowing: Organizational and intrapersonal variables. Nova Southeastern University. 
Smith, A., and E. C. Hume. (2005). Linking culture and ethics: A comparison of accountants' ethical belief systems in the individualism/collectivism and power distance contexts. Journal of Business Ethics, 62 (3), 209-220.

Sugiyono. (2013). Metode Penelitian Kuantitatif dan Kualitatif. R \& D. Bandung: Alfabeta.

Taylor, E. Z., \& Curtis, M. B. (2013). Whistleblowing in audit firms : Organizational response and power distance. Behavioral Research in Accounting. 25(2), 21-43.

Taylor, E. Z., M. B. Curtis, and L. Chui. (2012). View from the other side: Staff auditors' observations of questionable peer behavior. CPA Journal. 6, 66-71.

Wijaya, S. 2016. Pengaruh penalaran moral, retaliasi, komitmen organisasi, dan komitmen profesi terhadap intensi untuk melakukan whistleblowing. Skripsi. Fakultas Ekonomi, Universitas Negeri Jakarta.

Wong-On-Wing, Bernard dan Lui, G (2013). Beyond cultural values: An implicit thery approachh to cross-cultural research in accounting ehics. American Accounting Association, 25(1), 15-36.

Yaya, R. L. (2017). Whistleblowing dan faktor-faktor yang memengaruhi niat melaksanakannya oleh aparatur sipil negara. Jurnal Akuntansi, 21(03):,336-350

Zalmi, W. D. (2018). Pengaruh komitmen profesional, locus of control, dan sosialisasi antisipatif mahasiswa terhadap whistleblowing. Jurnal Eksplorasi Akuntansi, 5, 290-305. 